\title{
How Does HTLV-1 Undergo Oncogene-Dependent Replication Despite a Strong Immune Response?
}

\author{
Hélène Gazon 1,2, Pradeep Chauhan ${ }^{1,2}$, Malik Hamaidia ${ }^{1,2}$, Clotilde Hoyos ${ }^{1,2}$, Lin Li ${ }^{1,2}$, \\ Roghaiyeh Safari ${ }^{1,2}$ and Luc Willems ${ }^{1,2 *}$ \\ ${ }^{1}$ National Fund for Scientific Research, Molecular and Cellular Epigenetics, Interdisciplinary Cluster for Applied \\ Genoproteomics, Liège, Belgium, ${ }^{2}$ Molecular Biology, TERRA, Gemboux Agro-Bio Tech, Gembloux, Belgium
}

In 1987, Mitsuaki Yoshida proposed the following model (Yoshida and Seiki, 1987): “... T-cells activated through the endogenous p40x would express viral antigens including the envelope glycoproteins which are exposed on the cell surface. These glycoproteins are targets of host immune surveillance, as is evidenced by the cytotoxic effects of antienvelope antibodies or patient sera. Eventually all cells expressing the viral antigens, that is, all cells driven by the p40x would be rejected by the host. Only those cells that did not express the viral antigens would survive. Later, these antigen-negative infected cells would begin again to express viral antigens, including p40x, thus entering into

OPEN ACCESS

Edited by:

Umberto Bertazzoni,

University of Verona, Italy

Reviewed by:

Charles R. Bangham, Imperial College London,

United Kingdom

Roberto S. Accolla

University of Insubria, Italy

*Correspondence:

Luc Willems

luc.willems@Uliege.be

Specialty section: This article was submitted to Virology,

a section of the journal

Frontiers in Microbiology

Received: 21 November 2017

Accepted: 26 December 2017

Published: 15 January 2018

Citation:

Gazon H, Chauhan P, Hamaidia M,

Hoyos C, Li L, Safari R and

Willems $L$ (2018) How Does HTLV-1

Undergo Oncogene-Dependent

Replication Despite a Strong Immune

Response? Front. Microbiol. 8:2684.

doi: 10.3389/fmicb.2017.02684 the second cycle of cell propagation. These cycles would be repeated in so-called healthy virus carriers for 20 or 30 years or longer...." Three decades later, accumulated experimental facts particularly on intermittent viral transcription and regulation by the host immune response appear to prove that Yoshida was right. This Hypothesis and Theory summarizes the evidences that support this paradigm.

Keywords: HTLV, BLV, microRNA, cytotoxic T cells, long non-coding RNA, Leukemia

\section{INTRODUCTION}

At least 20 million people worldwide are infected with human T-cell leukemia virus type 1 (HTLV-1) (Gessain and Cassar, 2012; Bangham, 2017; Watanabe, 2017). This retrovirus is prevalent in southwestern Japan, sub-Saharan Africa, the Caribbean islands, South America, the Middle East and Austro-Melanesia. Transmission occurs principally from mother to child via milk or between sexual partners through contaminated blood. Infected individuals are at risk of developing a rapidly progressive malignancy, adult T-cell leukemia/lymphoma (ATLL), and a debilitating neurologic condition, HTLV-1 associated myelopathy/tropical spastic paraparesis (HAM/TSP) (Willems et al., 2017).

Although frequently neglected in the field, bovine leukemia virus (BLV) is a useful model to address specific questions that cannot be answered in the HTLV-1 system (Rodríguez et al., 2011; Polat et al., 2017). Both viruses are indeed closely related $\delta$-retroviruses that induce hematological diseases. In the bovine species, the most prevalent clinical manifestation in about one-third of infected animals is persistent lymphocytosis, a benign accumulation of infected B-lymphocytes (Gutierrez et al., 2014). In a minority of cases (about 5-10\%), BLV infection can progress to fatal leukemia/lymphoma whose most dramatic consequence is spleen hypertrophy and disruption consecutive to tumor formation. BLV typically persists in less than $1 \%$ of peripheral blood cells, leading to an asymptomatic infection in the majority of infected animals. BLV is transmitted 
horizontally by direct contact, iatrogenic procedures or insect bites upon transfer of infected cells from milk, blood, and body fluids from heavily infected dams (Barez et al., 2015).

\section{THE PARADOX: HTLV-1 REPLICATION IS DRIVEN BY ONCOGENIC PROTEINS THAT EXPOSE THE INFECTED CELL TO THE HOST IMMUNE RESPONSE}

According to currently most accepted model, two viral proteins (Tax and HBZ, HTLV-1 bZIP) are hypothesized to have the highest impact on viral replication and cell transformation (Matsuoka and Jeang, 2007; Carpentier et al., 2015). The modes of action of Tax and HBZ are remarkably pleiotropic and involve a variety of cell signaling pathways (CREB, NF- $\kappa \mathrm{B}$, AKT, and TNF) (Twizere et al., 2003; Boxus et al., 2008). Tax inhibits tumor suppressors (p53, Bcl11B, and TP53INP1) and activates cyclin-dependent kinases (CDKs), both of these mechanisms leading to accelerated cell proliferation. Experimental evidence further shows that Tax drives tumor formation in transgenic mouse models, supporting its oncogenic potential. Through an interaction with the helicase complex (mcm2-7), Tax accelerates $S$ phase progression by initiating additional replication origins. By promoting unscheduled cell growth, Tax also induces genomic instability and generates somatic alterations. Another viral protein, HBZ also favors cell proliferation by inhibiting apoptosis/senescence and modulating the cell cycle (Ma et al., 2016). In fact, the HBZ protein counteracts a series of Tax-activated viral and cellular pathways (such as NF- $\mathrm{B}$, Akt, and CREB). Transgenic expression of HBZ in CD4 $+\mathrm{T}$ cells induced T-cell lymphomas and systemic inflammation in mice, resembling diseases observed in HTLV-1 infected individuals (Satou et al., 2011).

A major issue of expression of viral proteins is initiation of the host immune response. Indeed, Tax induces a strong immune response that would be harmful to infected cells (Nagai et al., 2001; Kannagi et al., 2005; Rowan et al., 2014). In comparison, HBZ triggers a less efficient immunity that is consistent with low expression low expression throughout HTLV1 infection (MacNamara et al., 2010). How does HTLV-1 persist despite a strong immune response against viral oncogenes that promote infected cell replication? The next paragraph lists the experimental evidence pertaining to this paradox.

\section{EXPERIMENTAL EVIDENCE AND INTERPRETATIONS}

\section{Evidence 1: Infected Cells Proliferate Faster to Undergo Clonal Expansion}

The BLV model has been instrumental to quantify the dynamics of cell turnover in vivo (Florins et al., 2007). Experiments based on intravenous injection of bromodeoxyuridine (BrdU) and carboxyfluorescein diacetate succinimidyl ester (CFSE) demonstrate that B-lymphocytes are proliferating significantly faster in BLV-infected sheep than in healthy controls (Debacq et al., 2002, 2006). Excess of proliferation is compensated by an increase in cell death, thereby maintaining homeostasis. Increased cell proliferation is also reported in HTLV-induced HAM/TSP using a similar strategy based on incorporation of deuterated glucose (Asquith et al., 2007). In vivo, BLV and HTLV infection is thus characterized by an increased cell turnover, likely driven by viral oncogenes such as Tax and HBZ.

\section{Evidence 2: 5' LTR Directed Transcription Is Extremely Low in Situ}

The amount of viral RNA transcribed from the $5^{\prime}$ LTR promoter is extremely low in vivo. In primary tumor cells, only very sensitive techniques such as RT-PCR can identify viral RNA transcribed from the 5' LTR promoter (Lagarias and Radke, 1989; Rovnak and Casey, 1999; Shimizu-Kohno et al., 2011; Demontis et al., 2015). It was initially concluded that the provirus is silent. However, in situ experiments showed that rare cells expressed large amounts of viral transcripts (Lagarias and Radke, 1989).

\section{Evidence 3: Sense Transcription Can Be Activated by Various Stimuli}

The main regulatory element of the $5^{\prime}$ LTR promoter that is activated by Tax is a 21 bp enhancer that interacts with CREB/ATF transcription factors (Suzuki et al., 1993; Adam et al., 1996). This complex activates sense transcription when cells are isolated ex vivo from HTLV-1 carriers or BLV-infected sheep. This reactivation can further be increased by various stimuli such as polyclonal activators, HDAC inhibitors or oxygen deprivation (Kerkhofs et al., 1996; Achachi et al., 2005; Tajima and Aida, 2005; Lezin et al., 2007; Olindo et al., 2011; Kulkarni et al., 2017).

\section{Evidence 4: Immunity against Most Viral Antigens Is Extremely Efficient While HBZ Is Poorly Immunogenic}

Persistent infection by BLV and HTLV-1 is characterized by a permanent and vigorous immunity against viral antigens (Kannagi et al., 2005; Burbelo et al., 2008; Bangham et al., 2009; Kattan et al., 2009). This immune response efficiently controls viral replication in vivo as demonstrated in the BLV model (Florins et al., 2006, 2009, 2011; Gillet et al., 2013). Among viral proteins, Tax is the immunodominant HTLV-1 antigen in the T-cell response (Kannagi et al., 1991; Goon et al., 2004). In contrast, the HBZ protein is very poorly immunogenic and expressed at very low levels in infected cells (Suemori et al., 2009; Enose-Akahata et al., 2013; Rowan et al., 2014; Raval et al., 2015; Baratella et al., 2017). Humoral immunity against HBZ protein is indeed particularly weak (Raval et al., 2015; Shiohama et al., 2016). However, cytotoxic $\mathrm{T}$ cells specific to HBZ but not to the immunodominant Tax are the most effective in the control of HTLV-1 (MacNamara et al., 2010). These results thus focus attention on the extremely low expression and low immunogenicity of HBZ. 


\section{Evidence 5: Antisense Transcripts and microRNAs Are Abundantly and Permanently Expressed in Tumors}

In contrast to $5^{\prime}$ LTR directed transcription, antisense RNA synthesis initiating at the $3^{\prime}$ LTR is consistently identified in primary ATL cells and BLV tumors (Usui et al., 2008; Saito et al., 2009; Durkin et al., 2016). In contrast to HTLV-1, BLV also abundantly transcribes a cluster of microRNAs from internal pol III promoters (Kincaid et al., 2012; Rosewick et al., 2013; Van Driessche et al., 2016). These microRNAs are required for efficient viral replication and induction of pathogenesis (Gillet et al., 2016).

\section{Evidence 6: HBZ and AS RNAs Are Mainly Localized in the Nucleus Suggesting a Role in Epigenetics}

The HBZ RNA is mainly localized in the nucleus, consistent with a low rate of translation (Hivin et al., 2005; Rende et al., 2011; Shimizu-Kohno et al., 2011; Li et al., 2012; Raval et al., 2015). Although the function of the HBZ protein has been clearly evidenced, the dominant nuclear localization of the HBZ RNA thus suggests other regulatory roles such as for example epigenetic modulation of gene expression. In BLV, the antisense transcripts are not predicted to be translated but are rather primarily retained in the nucleus, hinting at a lncRNA-like role (Durkin et al., 2016).

\section{Evidence 7: Untranslated HBZ RNA Has a Function}

The oncogenic role of the HBZ RNA was revealed by an untranslatable HBZ RNA (i.e., devoid of initiation codon) able to induce the proliferation of a human IL-2-dependent T-cell line (Kit225) (Satou et al., 2006). Microarray expression analysis reveals that $\mathrm{HBZ}$ RNA and protein differentially modulate the transcription of host genes. HBZ RNA activates the transcription of survivin and cell-cycle related genes (Mitobe et al., 2015). Thus, the HBZ gene has bimodal functions in two different molecular forms as a polypeptide and a ribonucleic acid. Notwithstanding important activities as protein, the scarcity of the HBZ polypeptide in tumor cells contrasts with the expression of the HBZ RNA. Therefore, main functions of HBZ are exerted by its RNA form. Although the level of expression of HBZ protein is unquestionably very low, the protein must nevertheless play an essential role in the life-cycle of the virus because the coding sequence has been conserved during evolution in presence of a protective host immune response.

\section{Evidence 8: Alternate Transcription of Sense and Antisense Transcription}

Single cell analysis shows that the Tax RNA is expressed in bursts and is exported from the nucleus, whereas the majority of hbz RNA is retained (Billman et al., 2017). Time-lapse imaging of destabilized enhanced green fluorescent protein indicates that Tax expression is transient, fluctuates between on/off states and is detected only in HBZ-negative

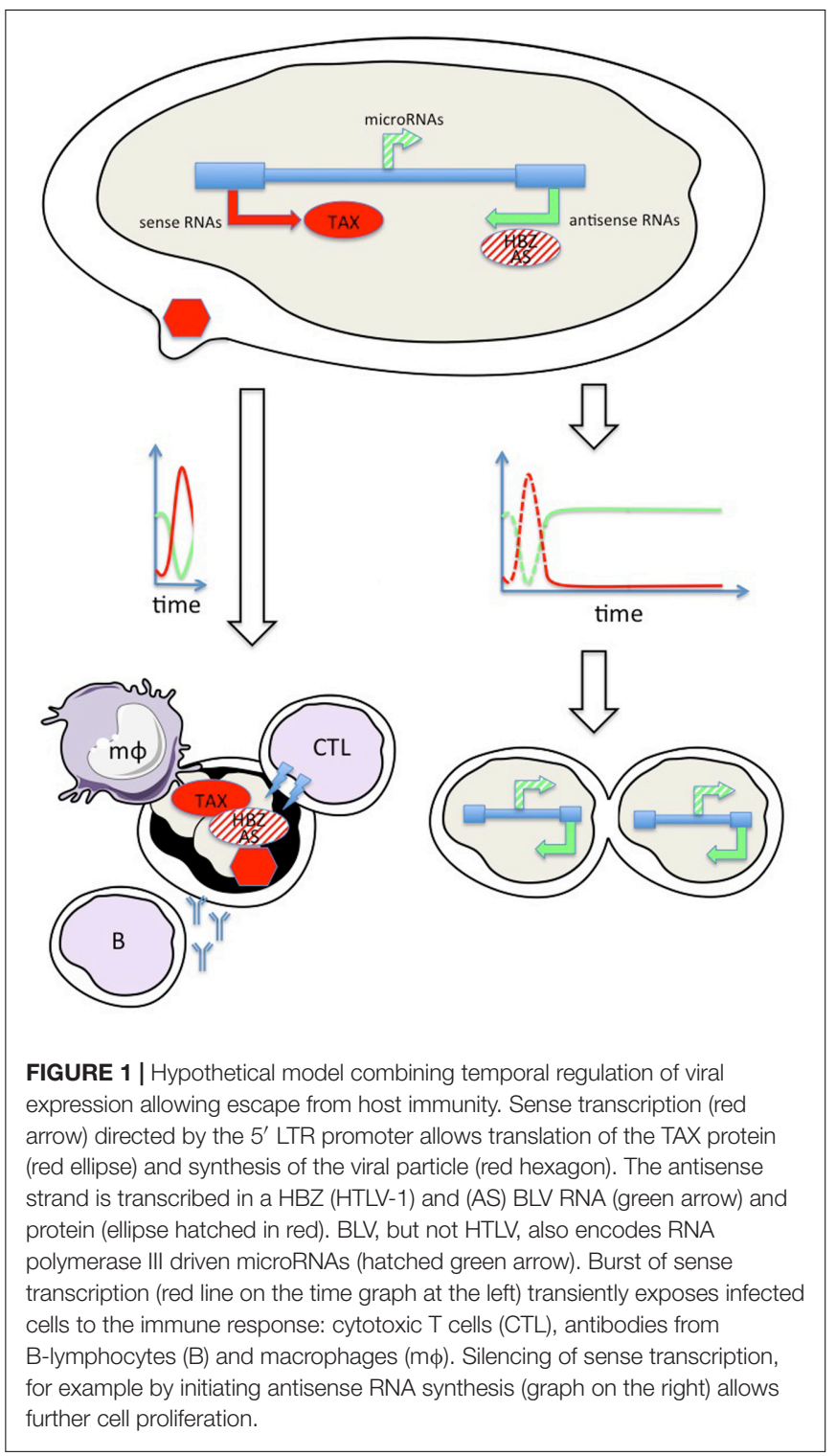

cells (Jasunaga and Matsuoka, 2017; Mahgoub et al., 2017). Viral persistence is thus characterized by successive cycles of sense/antisense transcription. Evidence from single-molecular RNA-FISH nevertheless indicates a more complex relationship between expression of the two strands that are not transcribed in strict alternation (Billman et al., 2017).

\section{A MODEL FOR VIRAL PERSISTENCE UNDER IMMUNE CONTROL}

These experimental evidences are consistent with the model presented in Figure 1 and support Yoshida's paradigm.

BLV/HTLV proviruses are transcribed in both orientations. Sense transcription from the $5^{\prime}$ LTR (red arrow) generates genomic and spliced subgenomic RNAs (e.g., Tax). Translation of these RNAs into oncogenic proteins (Tax) triggers cell 
proliferation, mitosis, and clonal expansion of the infected cell. Synthesis of structural (gag, env) and enzymatic (protease, reverse transcriptase, and integrase) proteins are required for assembly of the viral particle (red hexagon) that will further colonize new target cells. The provirus is also transcribed in the antisense orientation from the $3^{\prime}$ LTR (green arrow) yielding HBZ and AS RNAs for HTLV and $\mathrm{BLV}$, respectively. HBZ is very poorly translated while the coding potential of AS is ambiguous (hatched in red). Furthermore, the immunogenicity of HBZ is weak compared to all other viral antigens. BLV, but not HTLV, also encodes RNA polymerase III driven microRNAs (hatched green arrow). RNA synthesis from the $5^{\prime}$ LTR is mostly silent but burst of sense transcription (red line on the time graph) transiently exposes infected cells to the immune response (e.g., cytotoxic, humoral, and innate). The only option that allows survival is to silence sense transcription, for example by initiating antisense RNA synthesis (graph on the right). This simplified model is nevertheless incomplete because the infected cell is also exposed to the CTL response to HBZ providing that the protein is expressed. Experimental evidence indicates that the HBZ RNA is mostly nuclear and is therefore not translated. Single cell kinetics of RNA and protein expression would answer to this still unsolved question. Another issue is the role of the intrinsic immunity operating within virus-infected cells, i.e., restriction factors (RFs) inhibiting Tax function or reverse transcription of viral genome (Tosi et al., 2011; Bai and Nicot, 2015; Forlani et al., 2016).

\section{CONCLUSION}

Yoshida predicted that the Tax oncogene should be expressed in cycles to allow cell survival. Recent reports describing bursts between sense and antisense transcriptions are consistent with this hypothesis. Regular switches between $5^{\prime}$ and $3^{\prime}$ transcription indeed allows transient Tax expression and fast

\section{REFERENCES}

Achachi, A., Florins, A., Gillet, N., Debacq, C., Urbain, P., Foutsop, G. M., et al. (2005). Valproate activates bovine leukemia virus gene expression, triggers apoptosis, and induces leukemia/lymphoma regression in vivo. Proc. Natl. Acad. Sci. U.S.A. 102, 10309-10314. doi: 10.1073/pnas.0504 248102

Adam, E., Kerkhofs, P., Mammerickx, M., Burny, A., Kettmann, R., and Willems, L. (1996). The CREB, ATF-1, and ATF-2 transcription factors from bovine leukemia virus-infected B lymphocytes activate viral expression. J. Virol. 70, 1990-1999.

Asquith, B., Zhang, Y., Mosley, A. J., de Lara, C. M., Wallace, D. L., Worth, A., et al. (2007). In vivo T lymphocyte dynamics in humans and the impact of human T-lymphotropic virus 1 infection. Proc. Natl. Acad. Sci. U.S.A. 104, 8035-8040. doi: $10.1073 /$ pnas.0608832104

Bai, X. T., and Nicot, C. (2015). MiR-28-3p is a cellular restriction factor that inhibits human $\mathrm{T}$ cell leukemia virus, type 1 (HTLV-1) replication and virus infection. J. Biol. Chem. 290, 5381-5390. doi: 10.1074/jbc.M114.626325

Bangham, C. R. M. (2017). Human T cell leukemia virus type 1: persistence and pathogenesis. Annu. Rev. Immunol. 15, 25-53. doi: 10.1146/annurev-immunol042617-053222 silencing of viral expression. This mechanism would allow Tax-driven cell proliferation and synthesis of viral particles in presence of the host immunity. This model thus illustrates the dynamic equilibrium between a virus attempting to proliferate under a tight control exerted by the immune response.

\section{AUTHOR CONTRIBUTIONS}

All authors have contributed equally to this work. LW drafted the manuscript. All authors corrected, edited, and approved the paper.

\section{FUNDING}

This work was supported by the "Fonds National de la Recherche Scientifique" (FNRS), the Télévie, the Interuniversity Attraction Poles (IAP) Program "Virus-host interplay at the early phases of infection" BELVIR initiated by the Belgian Science Policy Office, the Belgian Foundation against Cancer (FBC), the "Centre Anticancéreux près ULg" (CAC), the "Subside Fédéral de Soutien à la Recherche and AgricultureIsLife" projects of Gembloux Agrobiotech (GxABT), the "ULg Fonds Spéciaux pour la Recherche" and the "Plan Cancer" of the "Service Public Fédéral." HG and RS (Télévie), CH (FNRS research fellow), and LW (Research Director) are members of the FNRS. PC was a Marie Curie COFUND postdoctoral fellow supported by European Union. LL and $\mathrm{MH}$ previously received support from AgricultureIsLife. $\mathrm{MH}$ and PC are presently fellows of the FBC. Nathalie Renotte and Jean-Rock Jacques provided skillful technical help.

\section{ACKNOWLEDGMENTS}

The authors thank the GIGA technology platforms.

Bangham, C. R. M., Meekings, K., Toulza, F., Nejmeddine, M., Majorovits, E., Asquith, B., et al. (2009). The immune control of HTLV-1 infection: selection forces and dynamics. Front. Biosci. 14:2889-2903. doi: 10.2741/3420

Baratella, M., Forlani, G., Raval, G. U., Tedeschi, A., Gout, O., Gessain, A., et al. (2017). Cytoplasmic localization of HTLV-1 HBZ protein: a biomarker of HTLV-1-associated myelopathy/tropical spastic paraparesis (HAM/TSP). PLOS Negl. Trop. Dis. 11:e0005285. doi: 10.1371/journal.pntd.0005285

Barez, P. Y., de Brogniez, A., Carpentier, A., Gazon, H., Gillet, N., Gutiérrez, G., et al. (2015). Recent advances in BLV research. Viruses 7, 6080-6088. doi: $10.3390 /$ v7112929

Billman, M. R., Rueda, D., and Bangham, C. R. M. (2017). Single-cell heterogeneity and cell-cycle-related viral gene bursts in the human leukaemia virus HTLV-1. Wellcome Open Res. 2:87. doi: 10.12688/wellcomeopenres. 12469.1

Boxus, M., Twizere, J.-C., Legros, S., Dewulf, J.-F., Kettmann, R., and Willems, L. (2008). The HTLV-1 Tax interactome. Retrovirology 5:76. doi: 10.1186/17424690-5-76

Burbelo, P. D., Meoli, E., Leahy, H. P., Graham, J., Yao, K., Oh, U., et al. (2008). Anti-HTLV antibody profiling reveals an antibody signature for HTLV-Iassociated myelopathy/tropical spastic paraparesis (HAM/TSP). Retrovirology 5:96. doi: 10.1186/1742-4690-5-96 
Carpentier, A., Gazon, H., de Brogniez, A., Willems, L., Carpentier, A., Barez, P.Y., et al. (2015). Modes of human T cell leukemia virus type 1 transmission, replication and persistence. Viruses 7, 3603-3624. doi: 10.3390/v7072793

Debacq, C., Asquith, B., Kerkhofs, P., Portetelle, D., Burny, A., Kettmann, R., et al. (2002). Increased cell proliferation, but not reduced cell death, induces lymphocytosis in bovine leukemia virus-infected sheep. Proc. Natl. Acad. Sci. U.S.A. 99, 10048-10053. doi: 10.1073/pnas.142100999

Debacq, C., Gillet, N., Asquith, B., Sanchez-Alcaraz, M. T., Florins, A., Boxus, M., et al. (2006). Peripheral blood B-cell death compensates for excessive proliferation in lymphoid tissues and maintains homeostasis in bovine leukemia virus-infected sheep. J. Virol. 80, 9710-9719. doi: 10.1128/JVI.01022-06

Demontis, M. A., Sadiq, M. T., Golz, S., and Taylor, G. P. (2015). HTLV-1 viral RNA is detected rarely in plasma of HTLV-1 infected subjects. J. Med. Virol. 87, 2130-2134. doi: 10.1002/jmv.24264

Durkin, K., Rosewick, N., Artesi, M., Hahaut, V., Griebel, P., Arsic, N., et al. (2016). Characterization of novel Bovine Leukemia Virus (BLV) antisense transcripts by deep sequencing reveals constitutive expression in tumors and transcriptional interaction with viral microRNAs. Retrovirology 13:33. doi: 10 . 1186/s12977-016-0267-8

Enose-Akahata, Y., Abrams, A., Massoud, R., Bialuk, I., Johnson, K. R., Green, P. L., et al. (2013). Humoral immune response to HTLV-1 basic leucine zipper factor (HBZ) in HTLV-1-infected individuals. Retrovirology 10:19. doi: 10.1186/17424690-10-19

Florins, A., de Brogniez, A., Elemans, M., Bouzar, A.-B., Francois, C., Reichert, M., et al. (2011). Viral expression directs the fate of B cells in bovine leukemia virus-infected sheep. J. Virol. 86, 621-624. doi: 10.1128/JVI.05718-11

Florins, A., Gillet, N., Asquith, B., Boxus, M., Burteau, C., Twizere, J., et al. (2007). Cell dynamics and immune response to BLV infection: a unifying model. Front. Biosci. 12, 1520-1531. doi: 10.2741/2165

Florins, A., Gillet, N., Asquith, B., Debacq, C., Jean, G., Schwartz-Cornil, I., et al. (2006). Spleen-dependent turnover of CD11b peripheral blood B lymphocytes in bovine leukemia virus-infected sheep. J. Virol. 80, 11998-12008. doi: 10.1128/ JVI.01447-06

Florins, A., Reichert, M., Asquith, B., Bouzar, A. B., Jean, G., François, C., et al. (2009). Earlier onset of $\delta$-retrovirus-induced leukemia after splenectomy. PLOS ONE 4:e6943. doi: 10.1371/journal.pone.0006943

Forlani, G., Abdallah, R., Accolla, R. S., and Tosi, G. (2016). The MHC class II transactivator CIITA inhibits the persistent activation of NF-kB by human $\mathrm{T}$ cell lymphotropic virus type-1 Tax-1 oncoprotein. J. Virol. 90, 3708-3721. doi: 10.1128/JVI.03000-15

Gessain, A., and Cassar, O. (2012). Epidemiological aspects and world distribution of HTLV-1 infection. Front. Microbiol. 3:388. doi: 10.3389/fmicb.2012. 00388

Gillet, N. A., Gutiérrez, G., Rodriguez, S. M., de Brogniez, A., Renotte, N., Alvarez, I., et al. (2013). Massive depletion of bovine leukemia virus proviral clones located in genomic transcriptionally active sites during primary infection. PLOS Pathog. 9:e1003687. doi: 10.1371/journal.ppat.1003687

Gillet, N. A., Hamaidia, M., de Brogniez, A., Gutiérrez, G., Renotte, N., Reichert, M., et al. (2016). Bovine leukemia virus small noncoding RNAs are functional elements that regulate replication and contribute to oncogenesis in vivo. PLOS Pathog. 12:e1005588. doi: 10.1371/journal.ppat.10 05588

Goon, P. K. C., Biancardi, A., Fast, N., Igakura, T., Hanon, E., Mosley, A. J., et al. (2004). Human T cell lymphotropic virus (HTLV) type-1-specific CD8 $+\mathrm{T}$ cells: frequency and immunodominance hierarchy. J. Infect. Dis. 189, 2294-2298. doi: 10.1086/420832

Gutierrez, G., Rodríguez, S. M., De Brogniez, A., Gillet, N., Golime, R., Burny, A., et al. (2014). Vaccination against $\delta$-retroviruses: the bovine leukemia virus paradigm. Viruses 6, 2416-2427. doi: 10.3390/v6062416

Hivin, P., Frédéric, M., Arpin-André, C., Basbous, J., Gay, B., Thébault, S., et al. (2005). Nuclear localization of HTLV-I bZIP factor (HBZ) is mediated by three distinct motifs. J. Cell Sci. 118, 1355-1362. doi: 10.1242/jcs. 01727

Jasunaga, J., and Matsuoka, M. (2017). Oncogenic spiral by infectious pathogens: the cooperation of multiple factors in cancer development. Cancer Sci. doi: 10.1111/cas.13443 [Epub ahead of print].

Kannagi, M., Harada, S., Maruyama, I., Inoko, H., Igarashi, H., Kuwashima, G., et al. (1991). Predominant recognition of human T cell leukemia virus type I
(HTLV-I) pX gene products by human CD8 + cytotoxic T cells directed against HTLV-I-infected cells. Int. Immunol. 3, 761-767. doi: 10.1093/intimm/3.8.761

Kannagi, M., Harashima, N., Kurihara, K., Ohashi, T., Utsunomiya, A., Tanosaki, R., et al. (2005). Tumor immunity against adult T-cell leukemia. Cancer Sci. 96, 249-255. doi: 10.1111/j.1349-7006.2005.00050.x

Kattan, T., MacNamara, A., Rowan, A. G., Nose, H., Mosley, A. J., Tanaka, Y., et al. (2009). The avidity and lytic efficiency of the CTL response to HTLV-1. J. Immunol. 182, 5723-5729. doi: 10.4049/jimmunol.0900069

Kerkhofs, P., Adam, E., Droogmans, L., Portetelle, D., Mammerickx, M., Burny, A., et al. (1996). Cellular pathways involved in the ex vivo expression of bovine leukemia virus. J. Virol. 70, 2170-2177.

Kincaid, R. P., Burke, J. M., and Sullivan, C. S. (2012). RNA virus microRNA that mimics a B-cell oncomiR. Proc. Natl. Acad. Sci. U.S.A. 109, 3077-3082. doi: 10.1073/pnas.1116107109

Kulkarni, A., Mateus, M., Thinnes, C. C., McCullagh, J. S., Schofield, C. J., Taylor, G. P., et al. (2017). Glucose metabolism and oxygen availability govern reactivation from latency of the human retrovirus HTLV-1. Cell Chem. Biol. 24, 1377.e-1387.e. doi: 10.1016/j.chembiol.2017.08.016

Lagarias, D. M., and Radke, K. (1989). Transcriptional activation of bovine leukemia virus in blood cells from experimentally infected, asymptomatic sheep with latent infections. J. Virol. 63, 2099-2107.

Lezin, A., Gillet, N., Olindo, S., Signaté, A., Grandvaux, N., Verlaeten, O., et al. (2007). Histone deacetylase mediated transcriptional activation reduces proviral loads in HTLV-1 associated myelopathy/tropical spastic paraparesis patients. Blood 110, 3722-3728. doi: 10.1182/blood-2007-04-085076

Li, M., Kannian, P., Yin, H., Kesic, M., and Green, P. L. (2012). Human T lymphotropic virus type 1 regulatory and accessory gene transcript expression and export are not rex dependent. AIDS Res. Hum. Retroviruses 28, 405-410. doi: 10.1089/aid.2011.0130

Ma, G., Yasunaga, J.-I., and Matsuoka, M. (2016). Multifaceted functions and roles of HBZ in HTLV-1 pathogenesis. Retrovirology 13:16. doi: 10.1186/s12977-0160249-x

MacNamara, A., Rowan, A., Hilburn, S., Kadolsky, U., Fujiwara, H., Suemori, K., et al. (2010). HLA class I binding of HBZ determines outcome in HTLV-1 infection. PLOS Pathog. 6:e1001117. doi: 10.1371/journal.ppat.1001117

Mahgoub, M., Yasunaga, J., Shimura, K., Furuta, R., and Matsuoka, M. (2017). "Transient tax expression is essential for ATL survival: insight based on single cell analysis," in Proceedings of the 18th International Conference on Human Retrovirology HTLV and Related Viruses, Tokyo.

Matsuoka, M., and Jeang, K.-T. (2007). Human T-cell leukaemia virus type 1 (HTLV-1) infectivity and cellular transformation. Nat. Rev. Cancer 7, 270-280. doi: $10.1038 / \mathrm{nrc} 2111$

Mitobe, Y., Yasunaga, J. I., Furuta, R., and Matsuoka, M. (2015). HTLV-1 bZIP Factor RNA and protein impart distinct functions on t-cell proliferation and survival. Cancer Res. 75, 4143-4152. doi: 10.1158/0008-5472.CAN-15-0942

Nagai, M., Kubota, R., Greten, T. F., Schneck, J. P., Leist, T. P., Jacobson, S., et al. (2001). Increased activated human T cell lymphotropic virus type I (HTLV-I) Tax11-19-specific memory and effector CD8 + cells in patients with HTLVI-associated myelopathy/tropical spastic paraparesis: correlation with HTLV-I provirus load. J. Infect. Dis. 183, 197-205. doi: 10.1086/317932

Olindo, S., Belrose, G., Gillet, N., Rodriguez, S., Boxus, M., Verlaeten, O., et al. (2011). Brief report safety of long-term treatment of HAM/TSP patients with valproic acid. Blood 118, 6306-6309. doi: 10.1182/blood-2011-04-349910

Polat, M., Takeshima, S., and Aida, Y. (2017). Epidemiology and genetic diversity of bovine leukemia virus. Virol. J. 14, 209. doi: 10.1186/s12985-017-0876-4

Raval, G. U., Bidoia, C., Forlani, G., Tosi, G., Gessain, A., and Accolla, R. S. (2015). Localization, quantification and interaction with host factors of endogenous HTLV-1 HBZ protein in infected cells and ATL. Retrovirology 12:59. doi: 10. 1186/s12977-015-0186-0

Rende, F., Cavallari, I., Corradin, A., Silic-Benussi, M., Toulza, F., Toffolo, G. M., et al. (2011). Kinetics and intracellular compartmentalization of HTLV-1 gene expression: nuclear retention of HBZ mRNAs. Blood 117, 4855-4859. doi: 10. 1182/blood-2010-11-316463

Rodríguez, S. M., Florins, A., Gillet, N., de Brogniez, A., Sánchez-Alcaraz, M. T., Boxus, M., et al. (2011). Preventive and therapeutic strategies for bovine leukemia virus: lessons for HTLV. Viruses 3, 1210-1248. doi: 10.3390/v3071210

Rosewick, N., Momont, M., Durkin, K., Takeda, H., Caiment, F., Cleuter, Y., et al. (2013). Deep sequencing reveals abundant noncanonical retroviral microRNAs 
in B-cell leukemia/lymphoma. Proc. Natl. Acad. Sci. U.S.A. 110, 2306-2311. doi: $10.1073 /$ pnas.1213842110

Rovnak, J., and Casey, J. W. (1999). Assessment of bovine leukemia virus transcripts in vivo. J. Virol. 73, 8890-8897.

Rowan, A. G., Suemori, K., Fujiwara, H., Yasukawa, M., Tanaka, Y., Taylor, G. P., et al. (2014). Cytotoxic T lymphocyte lysis of HTLV-1 infected cells is limited by weak HBZ protein expression, but non-specifically enhanced on induction of Tax expression. Retrovirology 11:116. doi: 10.1186/s12977-014-0116-6

Saito, M., Matsuzaki, T., Satou, Y., Yasunaga, J.-I., Saito, K., Arimura, K., et al. (2009). In vivo expression of the HBZ gene of HTLV-1 correlates with proviral load, inflammatory markers and disease severity in HTLV-1 associated myelopathy/tropical spastic paraparesis (HAM/TSP). Retrovirology 6:19. doi: 10.1186/1742-4690-6-19

Satou, Y., Yasunaga, J., Yoshida, M., and Matsuoka, M. (2006). HTLV-I basic leucine zipper factor gene mRNA supports proliferation of adult T cell leukemia cells. Proc. Natl. Acad. Sci. U.S.A. 103, 720-725. doi: 10.1073/pnas.0507631103

Satou, Y., Yasunaga, J., Zhao, T., Yoshida, M., Miyazato, P., Takai, K., et al. (2011). HTLV-1 bZIP factor induces T-cell lymphoma and systemic inflammation in vivo. PLOS Pathog. 7:e1001274. doi: 10.1371/journal.ppat.1001274

Shimizu-Kohno, K., Satou, Y., Arakawa, F., Kiyasu, J., Kimura, Y., Niino, D., et al. (2011). Detection of HTLV-1 by means of HBZ gene in situ hybridization in formalin-fixed and paraffin-embedded tissues. Cancer Sci. 102, 1432-1436. doi: 10.1111/j.1349-7006.2011.01946.x

Shiohama, Y., Naito, T., Matsuzaki, T., Tanaka, R., Tomoyose, T., Takashima, H., et al. (2016). Absolute quantification of HTLV-1 basic leucine zipper factor (HBZ) protein and its plasma antibody in HTLV-1 infected individuals with different clinical status. Retrovirology 13:29. doi: 10.1186/s12977-016-0263-Z

Suemori, K., Fujiwara, H., Ochi, T., Ogawa, T., Matsuoka, M., Matsumoto, T., et al. (2009). HBZ is an immunogenic protein, but not a target antigen for human T-cell leukemia virus type 1-specific cytotoxic T lymphocytes. J. Gen. Virol. 90, 1806-1811. doi: 10.1099/vir.0.010199-0

Suzuki, T., Fujisawa, J. I., Toita, M., and Yoshida, M. (1993). The trans-activator tax of human T-cell leukemia virus type 1 (HTLV-1) interacts with cAMPresponsive element (CRE) binding and CRE modulator proteins that bind to the 21-base-pair enhancer of HTLV-1. Proc. Natl. Acad. Sci. U.S.A. 90, 610-614. doi: 10.1073 /pnas.90.2.610

Tajima, S., and Aida, Y. (2005). Induction of expression of bovine leukemia virus (BLV) in blood taken from BLV-infected cows without removal of plasma. Microbes Infect. 7, 1211-1216. doi: 10.1016/j.micinf.2005.04.010
Tosi, G., Forlani, G., Andresen, V., Turci, M., Bertazzoni, U., Franchini, G., et al. (2011). Major histocompatibility complex class II transactivator CIITA is a viral restriction factor that targets human T-cell lymphotropic virus type 1 Tax-1 function and inhibits viral replication. J. Virol. 85, 10719-10729. doi: 10.1128/JVI.00813-11

Twizere, J.-C., Kruys, V., Lefèbvre, L., Vanderplasschen, A., Collete, D., Debacq, C., et al. (2003). Interaction of retroviral Tax oncoproteins with tristetraprolin and regulation of tumor necrosis factor-alpha expression. J. Natl. Cancer Inst. 95, 1846-1859. doi: 10.1093/jnci/djg118

Usui, T., Yanagihara, K., Tsukasaki, K., Murata, K., Hasegawa, H., Yamada, Y., et al. (2008). Characteristic expression of HTLV-1 basic zipper factor (HBZ) transcripts in HTLV-1 provirus-positive cells. Retrovirology 5:34. doi: 10.1186/ 1742-4690-5-34

Van Driessche, B., Rodari, A., Delacourt, N., Fauquenoy, S., Vanhulle, C., Burny, A., et al. (2016). Characterization of new RNA polymerase III and RNA polymerase II transcriptional promoters in the Bovine Leukemia Virus genome. Sci. Rep. 6:31125. doi: $10.1038 /$ srep31125

Watanabe, T. (2017). Adult T-cell leukemia (ATL): molecular basis for clonal expansion and transformation of HTLV-1-infected T cells. Blood 129, 1071-1081. doi: 10.1182/blood-2016-09-692574

Willems, L., Hasegawa, H., Accolla, R., Bangham, C., Bazarbachi, A., Bertazzoni, U., et al. (2017). Reducing the global burden of HTLV-1 infection: an agenda for research and action. Antiviral Res. 137, 41-48. doi: 10.1016/j.antiviral.2016. 10.015

Yoshida, M., and Seiki, M. (1987). Recent advances in the molecular biology of HTLV-1: trans-activation of viral and cellular genes. Annu. Rev. Immunol. 5, 541-557. doi: 10.1146/annurev.iy.05.040187.002545

Conflict of Interest Statement: The authors declare that the research was conducted in the absence of any commercial or financial relationships that could be construed as a potential conflict of interest.

Copyright (C) 2018 Gazon, Chauhan, Hamaidia, Hoyos, Li, Safari and Willems. This is an open-access article distributed under the terms of the Creative Commons Attribution License (CC BY). The use, distribution or reproduction in other forums is permitted, provided the original author(s) or licensor are credited and that the original publication in this journal is cited, in accordance with accepted academic practice. No use, distribution or reproduction is permitted which does not comply with these terms. 